\title{
miR-206 Expression Is Down-regulated in Estrogen Receptor $\alpha$-Positive Human Breast Cancer
}

\author{
Naoto Kondo, Tatsuya Toyama, Hiroshi Sugiura, Yoshitaka Fujii, and Hiroko Yamashita \\ Oncology, Immunology, and Surgery, Nagoya City University Graduate School of Medical Sciences, Nagoya, Japan
}

\begin{abstract}
Expression levels of estrogen receptor (ER) $\alpha$ govern estrogendependent growth, response to endocrine therapy, and prognosis in ER $\alpha$-positive breast cancer. Multiple mechanisms involved in altering ER $\alpha$ gene expression in breast cancer have been identified, including ER $\alpha$ gene amplification as well as transcriptional silencing by DNA methylation of CpG islands within the $\mathrm{ER} \alpha$ promoter and mutations within the open reading frame of ERo. However, expression levels of ER $\alpha$ in breast cancer tissues differ widely among patients, and frequently change during disease progression and in response to systemic therapies. Recent evidence has shown that microRNA mutations or misexpression correlate with various human cancers, and miR-206 is reported to decrease endogenous ER $\alpha$ mRNA and protein levels in human MCF-7 breast cancer cells via two specific target sites within the 3 -untranslated region of the human ER $\alpha$ transcript. In this study, we show for the first time that miR-206 expression is markedly decreased in ER $\alpha$-positive human breast cancer tissues assayed by quantitative reverse transcription-PCR analysis. Moreover, we observe that miR-206 expression is inversely correlated with ER $\alpha$ but not ER $\beta$ mRNA expression in breast cancer tissues. Transfection experiments revealed that introduction of miR-206 into estrogen-dependent MCF-7 breast cancer cells inhibits cell growth in a dose- and timedependent manner. Our results suggest that miR-206 could be a novel candidate for endocrine therapy that targets only ER $\alpha$ in breast cancer. [Cancer Res 2008;68(13):5004-8]
\end{abstract}

\section{Introduction}

Estrogen receptor (ER) $\alpha$ is essential for estrogen-dependent growth, and its level of expression is a crucial determinant of response to endocrine therapy and prognosis in ER $\alpha$-positive breast cancer. There is no doubt that the more ER $\alpha$ present in the tumor cells, the greater the likelihood of a favorable response to endocrine therapy (1). However, little is known about how the expression of $\mathrm{ER} \alpha$ in human breast cancer is regulated.

$\mathrm{ER} \alpha$ acts as a ligand-activated oncogene product in breast tissues. Expression of the human ER $\alpha$ gene (ESRI) is controlled at the transcriptional level by seven different promoters used in a cellspecific manner (2). This complex transcriptional unit can undergo alternative splicing, which has been shown to generate shorter ER $\alpha$ isoforms (3). Multiple mechanisms involved in the silencing of ESR1 gene expression in breast cancer have been identified,

Requests for reprints: Hiroko Yamashita, Oncology, Immunology and Surgery, Nagoya City University Graduate School of Medical Sciences, 1 Kawasumi, Mizuhocho, Mizuho-ku, Nagoya 467-8601, Japan. Phone: 1-81-52-853-8231; Fax: 1-81-52-8536440; E-mail: hirokoy@med.nagoya-cu.ac.jp.

(C)2008 American Association for Cancer Research.

doi:10.1158/0008-5472.CAN-08-0180 including mutations within the open reading frame (3) and transcriptional silencing by DNA methylation of promoterproximal CpG islands (4). It was recently reported that $\mathrm{ER} \alpha$ gene amplification is frequent in breast cancer and results in $\mathrm{ER} \alpha$ protein overexpression (5). However, breast cancer patients show a wide range of $\mathrm{ER} \alpha$ expression levels, and the levels of expression in individual patients change during disease progression and in response to systemic therapies. Therefore, other mechanisms may also regulate $\mathrm{ER} \alpha$ expression in breast cancer.

Recently, Adams and colleagues (6) reported that the microRNA miR-206 decreases endogenous ER $\alpha$ mRNA and protein levels in human MCF-7 breast cancer cells by acting through two specific miR-206 target sites within the $3^{\prime}$-untranslated region (UTR) of the human $\mathrm{ER} \alpha$ transcript. MicroRNAs (miRNA) are a class naturally occurring small noncoding RNAs that control gene expression by targeting mRNAs for translational repression or cleavage (7). Primary miRNA transcripts are cleaved into 70- to 80-nucleotide precursor miRNA (pre-miRNA) hairpins by RNase III Drosha in the cell nucleus and transported to the cytoplasm, where pre-miRNAs are processed by RNA Dicer into 19- to 25-nucleotide miRNA duplexes. One strand of each duplex is degraded, and the other strands become mature miRNAs, which, incorporated into the RNA-induced silencing complex, recognize sites in the 3 -UTR of the target mRNAs and cause translational repression or mRNA cleavage. miRNAs are a new player among gene regulation mechanisms, and their functions have not been fully explored but are known to include the regulation of cellular differentiation, proliferation, and apoptosis. Recent evidence has shown that miRNA mutations or misexpression are associated with various human cancers and indicates that miRNAs can function as tumor suppressors and oncogenes (8). MicroRNA expression profiling also revealed that miRNAs are differently expressed among molecular subtypes in breast cancer (9-11). Furthermore, recent studies have shown that loss or gain of function of specific miRNAs, such as let7 (12), miR-10b (13), miR-21 (14), and mir-17-5p (15), contributes to breast epithelial cellular transformation and tumorigenesis.

The present study was undertaken to assess the role of miR-206 in human breast cancer. We examined expression of miR-206 in $\mathrm{ER} \alpha$-positive and ER $\alpha$-negative human breast cancer tissues, and found for the first time that miR-206 expression was markedly decreased in ER $\alpha$-positive breast cancer. Growth inhibition of estrogen-dependent breast cancer cells transfected with miR-206 was also analyzed.

\section{Materials and Methods}

Breast cancer tissues and immunohistochemical analysis. Breast tumor specimens from female patients with invasive breast carcinoma, who were treated at Nagoya City University Hospital between 1996 and 2001, were included in this study. The study protocol was approved by the institutional review board and conformed to the guidelines of the 1975 Declaration of Helsinki. All patients had undergone surgical treatment for 


\begin{tabular}{|c|c|c|}
\hline & $\begin{array}{c}\text { ER } \alpha- \\
\text { positive (\%) }\end{array}$ & $\begin{array}{c}\text { ER } \alpha- \\
\text { negative (\%) }\end{array}$ \\
\hline Total number of patients & 49 & 45 \\
\hline \multicolumn{3}{|l|}{ Age (y) } \\
\hline$<50$ & $6(12)$ & $18(40)$ \\
\hline$\geq 50$ & $43(88)$ & $27(60)$ \\
\hline \multicolumn{3}{|l|}{ Tumor size $(\mathrm{cm})$} \\
\hline$\leq 2$ & $16(33)$ & $9(20)$ \\
\hline$>2$ & $33(67)$ & $36(80)$ \\
\hline \multicolumn{3}{|l|}{ No. of positive lymph nodes } \\
\hline 0 & $29(59)$ & $30(67)$ \\
\hline $1-3$ & $13(27)$ & $11(24)$ \\
\hline$>3$ & $7(14)$ & $4(19)$ \\
\hline \multicolumn{3}{|l|}{ Histology } \\
\hline Invasive ductal carcinoma & $41(84)$ & $38(84)$ \\
\hline Special types & $8(16)$ & $7(16)$ \\
\hline \multicolumn{3}{|l|}{ HER2 } \\
\hline Negative & $49(100)$ & $45(100)$ \\
\hline Positive & $0(0)$ & $0(0)$ \\
\hline
\end{tabular}

primary breast cancer (either mastectomy or lumpectomy). The samples were chosen from the continuous series of invasive carcinoma tissues. ER $\alpha$ protein expression status was confirmed by immunohistochemistry (IHC) as follows. One $4-\mu \mathrm{m}$ section of each submitted paraffin block was stained first with H\&E to verify that an adequate number of invasive carcinoma cells were present and that the fixation quality was adequate for IHC analysis. Serial sections $(4 \mu \mathrm{m})$ were prepared from selected blocks and float mounted on adhesive-coated glass slides, for staining with monoclonal mouse anti-human ER $\alpha$ antibody (1D5; DAKO) at 1:100 dilution as described previously (16). The DAKO Envision system (DAKO EnVisionlabeled polymer, peroxidase) was used for detection. After the entire slide was evaluated by light microscopy, expression of ER $\alpha$ was scored by proportion and intensity, according to Allred's procedure (17). In brief, the proportion score represented the estimated proportion of tumor cells staining positive was as follows: 0 (none), $1(<1 / 100), 2(1 / 100$ to $1 / 10)$, $3(1 / 10$ to $1 / 3), 4(1 / 3$ to $2 / 3)$, and $5(>2 / 3)$. Any brown nuclear staining in invasive breast epithelium counted toward the proportion score. The intensity score represented the average intensity of the positive cells was as follows: 0 (none), 1 (weak), 2 (intermediate), and 3 (strong). The proportion and intensity scores were then added to obtain a total score, which could range from 0 to 8 . Among 383 cases from which paired frozen tissue samples were available, 203 cases with HER2-negative tumors were used in this study from 246 cases which HER2 status was known. Forty-five tumors with scores of 0 to 2 made up the ER $\alpha$-negative group in this study, and 49 tumors with score 8 composed the ER $\alpha$-positive group. HER2-positive tumors were excluded in this study (Table 1).

Quantitative reverse transcription-PCR detection of miRNA. Total RNA was extracted from $\sim 500 \mathrm{mg}$ of frozen breast cancer tissue using TRIZOL reagent (Life Technologies, Inc.) as described previously (18). cDNA was reverse transcribed from total RNA samples using specific miRNA primers from the Taq Man MicroRNA Assays and reagents from the Taq Man MicroRNA Reverse Transcription kit (Applied Biosystems). The resulting cDNA was amplified by PCR using Taq Man MicroRNA Assay primers with the Taq Man Universal PCR Master Mix and analyzed with a 7500 ABI PRISM Sequence Detector System according to the manufacturer's
Figure 1. miR-206 expression is down-regulated in $\mathrm{ER} \alpha$-positive human breast cancer. $A$, quantitative RT-PCR detection analysis shows that expression levels of miR-206 are much higher in the $E R \alpha$-negative tumors than in the ER $\alpha$-positive tumors $(P=0.0001)$. $B$, quantitative RT-PCR detection analysis shows that expression levels of miR-30c are not different between $\mathrm{ER} \alpha$-negative and $\mathrm{ER} \alpha$-positive tumors. $C$, the relationship between $\mathrm{ER} \alpha$ protein expression scores and miR-206 expression in breast cancer tissues. miR-206 expression is gradually decreased as $\mathrm{ER} \alpha$ protein scores increase.

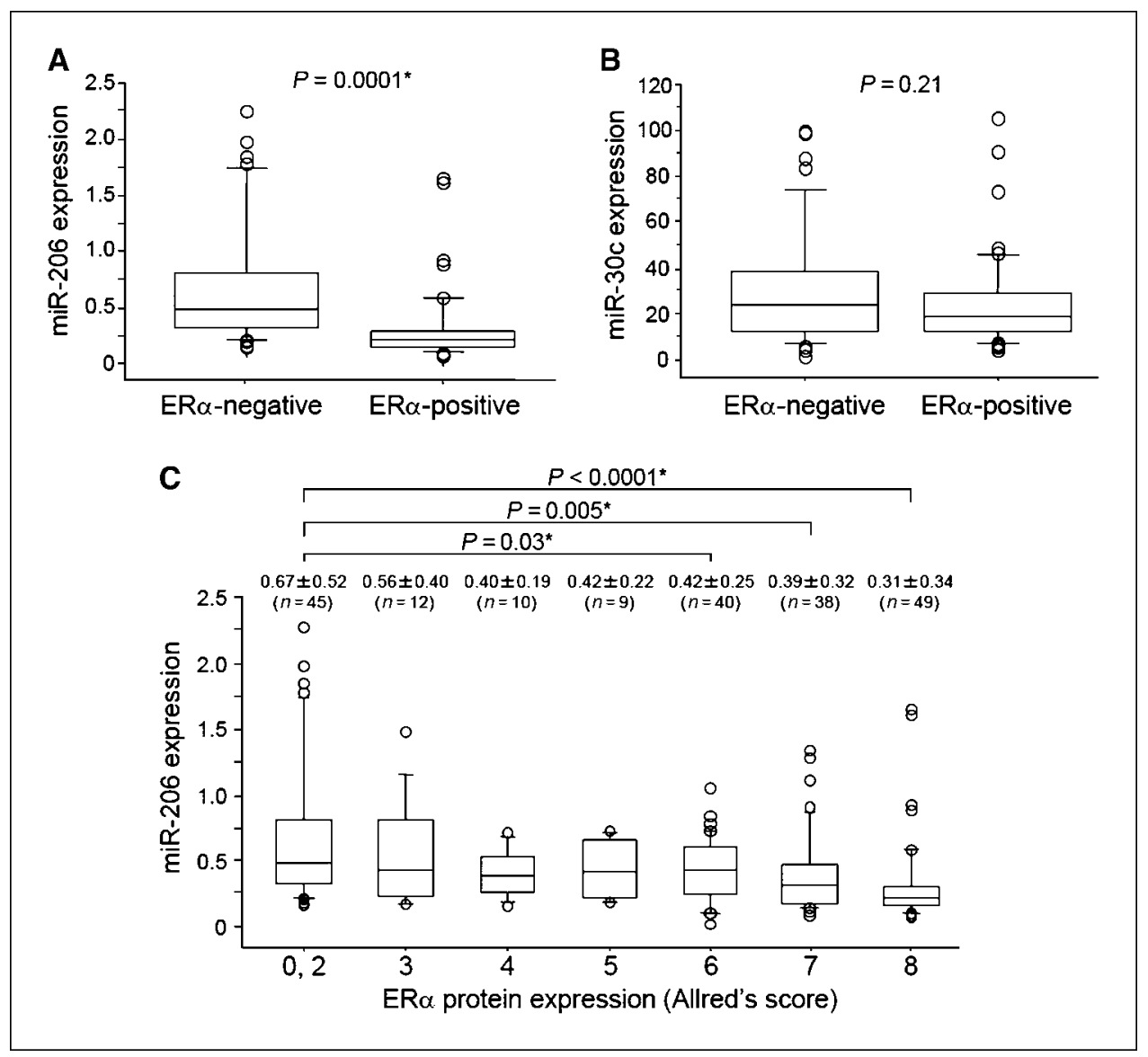



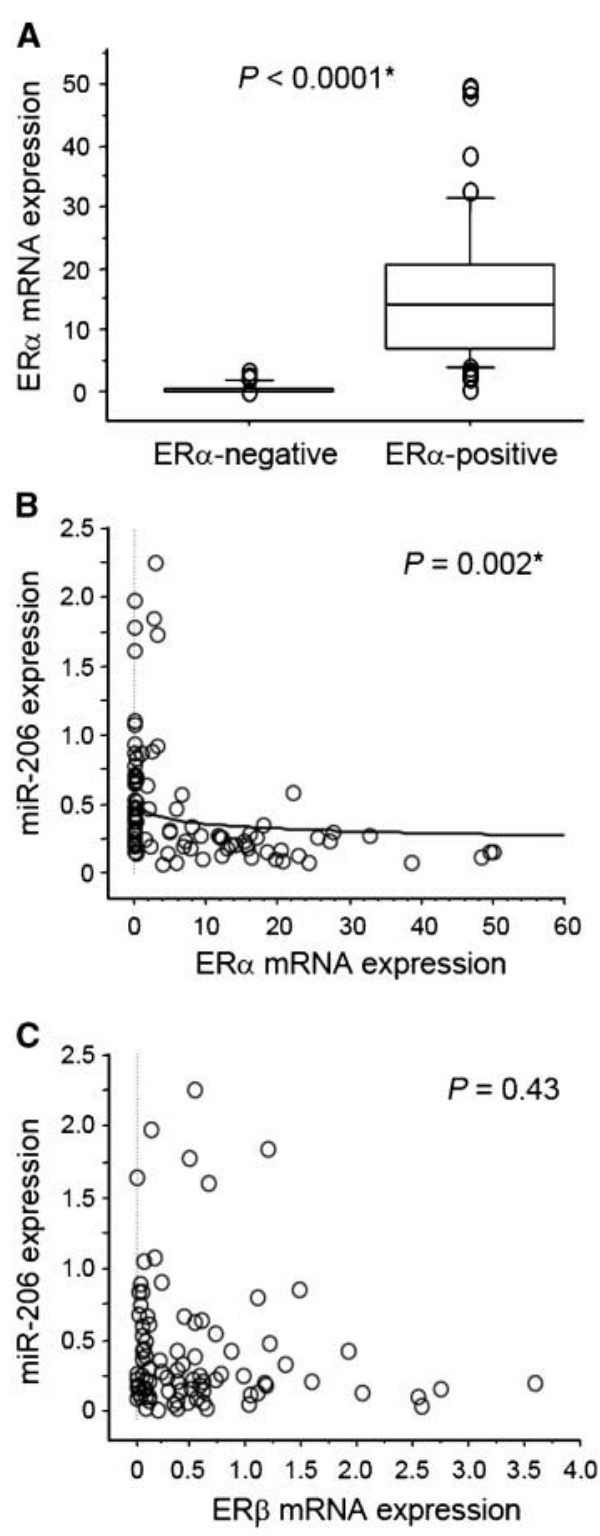

Figure 2. miR-206 expression is inversely correlated with expression of $\mathrm{ER} \alpha$ but not $E R \beta$ in human breast cancer tissues. $A$, quantitative RT-PCR detection analysis shows that expression levels of $\mathrm{ER} \alpha \mathrm{mRNA}$ are much higher in the $\mathrm{ER} \alpha$-positive tumors than in the $\mathrm{ER} \alpha$-negative tumors $(P<0.0001)$ $B$, scatterplots show inverse correlation between miR-206 and ER $\alpha$ mRNA expression in breast cancer tissues $(P=0.002)$. $C$, scatterplots show ER $\beta$ mRNA expression is not correlated with miR-206 expression in breast cancer tissues.

instructions (Applied Biosystems). The relative levels of miRNA expression were calculated from the relevant signals by normalization with the signal for U6B miRNA expression. The assay names for miR-206, miR-30c, and U6B were as follows: hsa-mir-206 for miR-206, hsa-mir-30c for miR-30c, and RNU6B for U6B miRNA (Applied Biosystems).

Quantitative RT-PCR detection of mRNA. Total RNA ( $1 \mu \mathrm{g})$ was subjected to reverse transcription with random primers in a $20 \mu \mathrm{L}$ reaction volume using High Capacity cDNA Reverse Transcription kit (Applied Biosystems). mRNA expression was measured by quantitative reversetranscription PCR (RT-PCR) with the Taq Man Universal PCR Master Mix using a 7500 ABI PRISM Sequence Detector System according to the manufacturer's instructions (Applied Biosystems). The relative levels of
mRNA expression were calculated from the relevant signals by normalization with the signal for glyceraldehyde-3-phosphate dehydrogenase $(G A P D H)$ mRNA expression. The assay numbers for $\mathrm{ER} \alpha, \mathrm{ER} \beta$, progesterone receptor (PR), cyclin D1, pS2, and GAPDH were as follows: Hs00174860_ml for ER $\alpha$, Hs00230957_ml for ERß, Hs00172183_ml for PR, Hs00277039_ml for cyclin D1, Hs00170216_ml for pS2, and Hs99999905_ml for GAPDH (Applied Biosystems).

Cell culture and transfections. MCF-7 cells (American Type Culture Collection) were grown in RPMI 1640 containing $10 \%$ fetal bovine serum (FBS), $2 \mathrm{mmol} / \mathrm{L}$ L-glutamine and penicillin-streptomycin $(50 \mathrm{IU} / \mathrm{mL}$ and $50 \mathrm{mg} / \mathrm{mL}$, respectively), at $37^{\circ} \mathrm{C}$ with $5 \% \mathrm{CO}_{2}$. Transfections of pre-miR206 precursor (hsa-miR-206; Ambion) were performed with Cell Line Nucleofector kits (Amaxa) using a Nucleofector device (Amaxa) according to the manufacturer's instructions. A nonspecific control miRNA (Anti-miR miRNA Inhibitors-Negative Control \#1; Ambion) was used as a negative control.

Cell proliferation assay. After transfection, MCF-7 cells (4,000 cells per well) were plated in 96-well plates and incubated in RPMI 1640 containing $10 \%$ FBS or in RPMI 1640 without phenol red containing $10 \%$ charcoal/ dextran-treated FBS (HyClone Laboratories), in the presence or absence of $17 \beta$-estradiol (E2, $10 \mathrm{nmol} / \mathrm{L}$; Sigma). Cell growth was measured using Cell Proliferation Reagent WST-1 (Roche Applied Science) by incubating cells for $3 \mathrm{~h}$ with the reagent and recording absorbance at $450 \mathrm{~nm}$ with a 96-well plate reader.

Statistical analysis. The unpaired Student's $t$ test was used to compare expression levels of miRNAs and mRNAs in ER $\alpha$-positive and ER $\alpha$-negative tumors. The differences between miR-206 expression levels corresponding to various $\mathrm{ER} \alpha$ protein scores were compared by one-way ANOVA followed by the Tukey-Kramer test. Correlation between miR-206 expression and $\mathrm{ER} \alpha$ and ER $\beta$ mRNA expression was assessed by regression analysis. Differences between treatments on cell growth were compared by one-way ANOVA followed by the Dunnett's test.

\section{Results}

miR-206 expression is down-regulated in ERo-positive human breast cancer. We first examined expression levels of miR-206 in ER $\alpha$-positive and $\mathrm{ER} \alpha$-negative human breast cancer tissues. Quantitative RT-PCR detection analysis showed that the expression levels of miR-206 were much higher in the ER $\alpha$-negative tumors $(0.67 \pm 0.52$; range, $0.15-2.25)$ than in the ER $\alpha$-positive tumors $(0.31 \pm 0.34$; range, $0.06-1.66 ; P=0.0001$; Fig. $1 A)$. We then tested expression of another miRNA, miR-30c, in the same tissues because it was reported that miR-30c expression, as assayed by microRNA microarray analysis, was increased in ER $\alpha$-positive compared with $\mathrm{ER} \alpha$-negative breast cancer (9). Our quantitative RT-PCR results showed no differences in miR-30c expression between $\mathrm{ER} \alpha$-negative and $\mathrm{ER} \alpha$-positive tumors (30.8 \pm 25.4 versus $24.7 \pm 20.8, P=0.21$; Fig. $1 B$ ). We then extended the analysis of miR-206 expression in breast cancer tissues to include all scores for $\mathrm{ER} \alpha$ protein expression, assessed semiquantitatively by IHC (Fig. 1C). miR-206 expression levels were gradually decreased as $\mathrm{ER} \alpha$ protein scores increased. We conclude that miR-206 expression is markedly decreased in $\mathrm{ER} \alpha$-positive human breast cancer tissues.

miR-206 expression is inversely correlated with ER $\alpha$ mRNA expression in human breast cancer. We next examined $\mathrm{ER} \alpha$ mRNA expression in human breast cancer tissues. As expected, the expression levels of $\mathrm{ER} \alpha$ mRNA were much higher in the ER $\alpha$-positive tumors $(16.1 \pm 12.1$; range, 0.08-50.00) than in the ER $\alpha$-negative tumors $(0.38 \pm 0.82$; range, 0.005-3.20; $P<0.0001$; Fig. $2 A$ ). To analyze the association between miR-206 expression and ER $\alpha$ mRNA expression, expression levels of miR-206 and ER $\alpha$ mRNA were plotted. The scatterplots showed that miR-206 
expression was inversely correlated with ER $\alpha$ mRNA expression in human breast cancer $(P=0.002$; Fig. $2 B)$. In contrast, no association was found between miR-206 expression and ER $\beta$ mRNA expression $(P=0.43$; Fig. $2 C)$.

miR-206 suppresses ER $\alpha$ expression and inhibits growth of MCF-7 cells. To assess the role of miR-206 in the growth of ER $\alpha$ positive breast cancer, pre-miR-206 precursor was introduced into proliferating MCF-7 cells. Cells were transfected with either control miRNA $(200 \mathrm{nmol} / \mathrm{L})$ or pre-miR-206 precursor at 20 or $200 \mathrm{nmol} / \mathrm{L}$ and incubated for up to 72 hours in a medium containing $10 \%$ FBS. A 3-(4,5-dimethylthiazol-2-yl)-2,5-diphenyltetrazolium bromide (MTT)-based cell proliferation assay revealed that miR-206 strongly inhibited cell growth in a dose- and time-dependent manner, whereas MCF-7 cells transfected with control miRNA continued to grow during the period (Fig. $3 A$ ). Introduction of miR-1, which is expressed in muscle cells and promotes their differentiation as well as miR-206 (19), also did not inhibit cell growth (data not shown). When MCF-7 cells were transfected with pre-miR-206 precursor at various concentrations and incubated for 72 hours, miR-206 induced a dose-dependent inhibition of cell growth (Fig. $3 B$ ). Introduction of pre-miR-206 precursor at $200 \mathrm{nmol} / \mathrm{L}$ into proliferating MCF-7 cells produced a significant $55 \%$ decrease in cell number compared with cells transfected with negative control $(P<0.0001$; Fig. $3 B$, top left $)$ Expression levels of ER $\alpha$ mRNA and miR-206 were quantitatively
Figure 3. Transfection of miR-206 into estrogen-dependent MCF-7 breast cancer cells suppresses ER $\alpha$ expression and inhibits cell growth. Representative experiments are shown in triplicate along with SD. A, MCF-7 cells were transfected with either control miRNA (200 $\mathrm{nmol} / \mathrm{L})$ or pre-miR-206 precursor at 20 or $200 \mathrm{nmol} / \mathrm{L}$ and incubated for up to $72 \mathrm{~h}$ in a medium containing $10 \%$ FBS. Cell growth was measured by an MTT-based cell proliferation assay. $B$, MCF-7 cells were transfected with either control miRNA $(200 \mathrm{nmol} / \mathrm{L})$ or pre-miR-206 precursor at 20 to $200 \mathrm{nmol} / \mathrm{L}$ and incubated for $72 \mathrm{~h}$ in a medium containing $10 \% \mathrm{FBS}$. ER $\alpha$ mRNA levels, miR-206 levels, and mRNA levels of PR, cyclin D1, and pS2 were measured by quantitative RT-PCR. $C$, MCF-7 cells were transfected with either control miRNA (200 nmol/L) or pre-miR-206 precursor $(200 \mathrm{nmol} / \mathrm{L})$ and incubated for up to $96 \mathrm{~h}$ in phenol red-free RPMI 1640 containing 10\% charcoal/dextran-treated FBS with or without $17 \beta$-estradiol (E2, $10 \mathrm{nmol} / \mathrm{L})$. Cell growth was measured by an MTT-based cell proliferation assay.

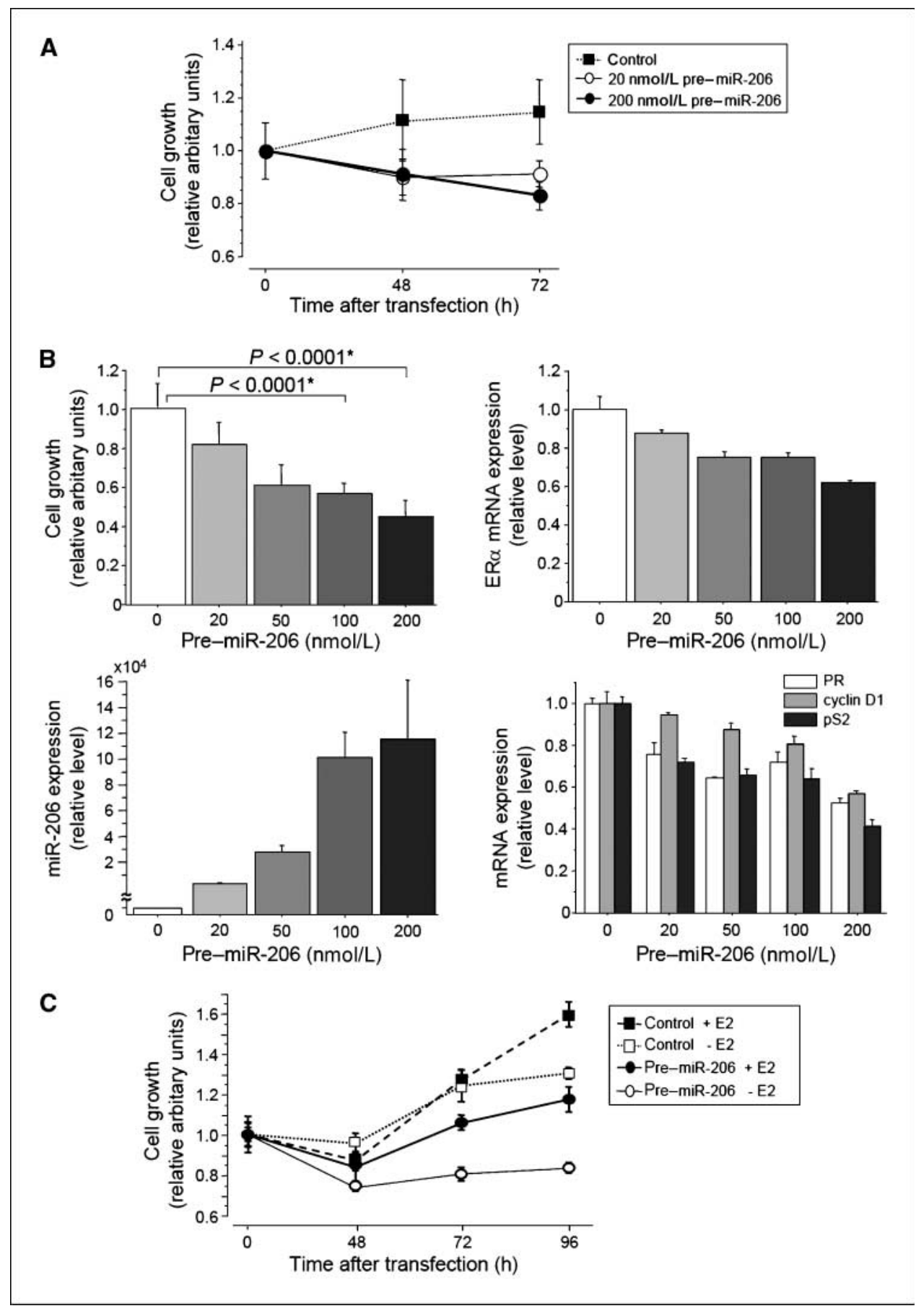


measured using parallel samples. Transfection with pre-miR-206 induced a dose-dependent repression of ER $\alpha$ mRNA levels, whereas it produced a dose-dependent increase of miR-206 levels (Fig. $3 B$, top right and bottom left). To further validate the effect of miR-206 on growth of MCF-7 cells, mRNA expression of ER $\alpha$-target genes, such as PR, cyclin D1, and pS2, was quantitatively measured using parallel samples (Fig. 3B, bottom right). Introduction of pre-miR-206 produced a dose-dependent decrease of mRNA expression of these genes. We then extended our analysis to determine whether miR206 would affect estrogen-induced growth of MCF-7 cells. Similar inhibition of growth by introduction of pre-miR-206 precursor at $200 \mathrm{nmol} / \mathrm{L}$ was observed when cells were cultured in a medium containing charcoal/dextran-treated FBS in the presence of E2 (control +E2 versus pre-miR-206 +E2; Fig. 3C). In the absence of $\mathrm{E} 2$, cell growth was also inhibited when cells were transfected with pre-miR-206 (control -E2 versus pre-miR-206 -E2; Fig. 3C). The cells may have been affected by low levels of estrogen present in serum because MCF-7 cells transfected with negative control grew slightly in the absence of added E2. From these analyses, we conclude that introduction of miR-206 into estrogen-dependent breast cancer cells leads to suppression of $\mathrm{ER} \alpha$ mRNA expression and inhibition of growth.

\section{Discussion}

In the present study, we have extended the basic, mechanistic insight by Adams and colleagues (6) to actual breast cancer by using clinically obtained tissue samples, and found that miR-206 expression is markedly decreased in $\mathrm{ER} \alpha$-positive human breast cancer tissues. We also showed that introduction of miR-206 into estrogen-dependent breast cancer cells leads to suppression of ER $\alpha$ expression and growth inhibition.

In experimental models, a single miRNA can regulate a number of genes (20). Previous studies have shown that miR-206 is expressed in skeletal and cardiac muscle and promotes muscle differentiation by down-regulating the p180 subunit of DNA polymerase $\alpha$ and myogenic transcription factors, Is1-3 and MyoR (19). Adams and colleagues (6) recently identified two miR-206 binding sites within the $3^{\prime}$-UTR of human $\mathrm{ER} \alpha$ and showed that miR-206 down-regulates ER $\alpha$ mRNA and protein expression in breast cancer cells. Our results show that the expression levels of
miR-206 are much higher in ER $\alpha$-negative than in ER $\alpha$-positive breast cancer tumors, and that the more ER $\alpha$-positive cells present in the tumor, the less miR-206 expression seen, suggesting that miR-206 is a key factor for the regulation of ER $\alpha$ expression in development and progression of human breast cancer.

Endocrine therapy has become the most important treatment option for women with $\mathrm{ER} \alpha$-positive breast cancer, and $\sim 70 \%$ of primary breast cancers express ER $\alpha$. Although endocrine therapy inhibits estrogen-dependent growth via $\mathrm{ER} \alpha$, the currently available treatments, such as selective ER modulators and estrogen deprivation therapy, affect the functions of both ER $\alpha$ and ER $\beta$. In this study, we show that miR-206 expression is inversely correlated with expression of $\mathrm{ER} \alpha$ but not $\mathrm{ER} \beta$ in human breast cancer tissues, and that introduction of miR-206 into estrogen-dependent breast cancer cells suppresses ER $\alpha$ expression and inhibits cell growth. Our results suggest that miR-206 would be a novel tool for endocrine therapy that targets only $\mathrm{ER} \alpha$.

To analyze the role of miR-206 in development of breast cancer could also be important for identifying the different molecular mechanisms between ER $\alpha$-positive and $\mathrm{ER} \alpha$-negative breast cancers. In addition, miR-206 may serve as a key factor that regulates $\mathrm{ER} \alpha$ expression during the development of normal breast epithelium because the expression of miR-206 is under hormonal regulation (6), although the role of miR-206 in normal breast tissues has not been studied.

In conclusion, the present data indicate for the first time that miR206 expression is markedly decreased in ER $\alpha$-positive human breast cancer tissues and that introduction of miR-206 into estrogendependent breast cancer cells inhibits cell growth. miR-206 could be a novel candidate for $\mathrm{ER} \alpha$-specific endocrine therapy in breast cancer.

\section{Disclosure of Potential Conflicts of Interest}

No potential conflicts of interest were disclosed.

\section{Acknowledgments}

Received 1/15/2008; revised 3/29/2008; accepted 5/13/2008.

The costs of publication of this article were defrayed in part by the payment of page charges. This article must therefore be hereby marked advertisement in accordance with 18 U.S.C. Section 1734 solely to indicate this fact.

We thank Mariko Nishio for her excellent technical assistance.

\section{References}

1. Yamashita H, Ando Y, Nishio M, et al. Immunohistochemical evaluation of hormone receptor status for predicting response to endocrine therapy in metastatic breast cancer. Breast Cancer 2006;13:74-83.

2. Reid G, Denger S, Kos M, Gannon F. Human estrogen receptor- $\alpha$ : regulation by synthesis, modification and degradation. Cell Mol Life Sci 2002;59:821-31.

3. Herynk MH, Fuqua SA. Estrogen receptor mutations in human disease. Endocr Rev 2004;25:869-98.

4. Giacinti L, Claudio PP, Lopez M, Giordano A. Epigenetic information and estrogen receptor $\alpha$ expression in breast cancer. Oncologist 2006;11:1-8.

5. Holst F, Stahl PR, Ruiz C, et al. Estrogen receptor a (ESR1) gene amplification is frequent in breast cancer. Nat Genet 2007;39:655-60.

6. Adams BD, Furneaux H, White BA. The microribonucleic acid (miRNA) miR-206 targets the human estrogen receptor- $\alpha(\mathrm{ER} \alpha)$ and represses $\mathrm{ER} \alpha$ messenger RNA and protein expression in breast cancer cell lines. Mol Endocrinol 2007;21:1132-47.

7. Chen K, Rajewsky N. The evolution of gene regulation by transcription factors and microRNAs. Nat Rev Genet 2007;8:93-103.

8. Esquela-Kerscher A, Slack FJ. Oncomirs - microRNAs with a role in cancer. Nat Rev Cancer 2006;6:259-69.

9. Iorio MV, Ferracin M, Liu CG, et al. MicroRNA gene expression deregulation in human breast cancer. Cancer Res 2005;65:7065-70.

10. Sempere LF, Christensen M, Silahtaroglu A, et al. Altered MicroRNA expression confined to specific epithelial cell subpopulations in breast cancer. Cancer Res 2007;67:11612-20.

11. Blenkiron C, Goldstein LD, Thorne NP, et al MicroRNA expression profiling of human breast cancer identifies new markers of tumor subtype. Genome Biol 2007;8:R214

12. Yu F, Yao H, Zhu P, et al. let-7 Regulates self renewal and tumorigenicity of breast cancer cells. Cell 2007;131: 1109-23.

13. Ma L, Teruya-Feldstein J, Weinberg RA. Tumour invasion and metastasis initiated by microRNA-10b in breast cancer. Nature 2007;449:682-8.

14. Si ML, Zhu S, Wu H, Lu Z, Wu F, Mo YY. miR-21 mediated tumor growth. Oncogene 2007;26:2799-803.
15. Hossain A, Kuo MT, Saunders GF. Mir-17-5p regulates breast cancer cell proliferation by inhibiting translation of AIB1 mRNA. Mol Cell Biol 2006;26: 8191-201.

16. Yamashita $\mathrm{H}$, Nishio M, Kobayashi S, et al. Phosphorylation of estrogen receptor $\alpha$ serine 167 is predictive of response to endocrine therapy and increases postrelapse survival in metastatic breast cancer. Breast Cancer Res 2005;7:R753-64.

17. Allred DC, Harvey JM, Berardo M, Clark GM Prognostic and predictive factors in breast cancer by immunohistochemical analysis. Mod Pathol 1998;11: 155-68.

18. Sugiura H, Toyama T, Hara Y, et al. Expression of estrogen receptor $\beta$ wild-type and its variant $E R \beta c x / \beta 2$ is correlated with better prognosis in breast cancer. Jpn J Clin Oncol 2007;37:820-8.

19. Kim HK, Lee YS, Sivaprasad U, Malhotra A, Dutta A. Muscle-specific microRNA miR-206 promotes muscle differentiation. J Cell Biol 2006;174:677-87.

20. Lim LP, Lau NC, Garrett-Engele P, et al. Microarray analysis shows that some microRNAs downregulate large numbers of target mRNAs. Nature 2005;433:769-73. 